\title{
Gerenciamento tributário: evidências empíricas no mercado segurador brasileiro
}

Tax management: empirical evidence in the Brazilian insurance market

Gestión tributaria: evidencias empíricas en mercado de seguros de Brasil

\section{Guilherme Otávio Monteiro Guimarães}

Mestre em Ciências Contábeis pelo Programa de Pós-Graduação em Ciências Contábeis da UFRJ

Endereço Av. Pasteur, 250 - sala 250, Urca

CEP: 22.290-250 - Rio de Janeiro/RJ- Brasil

e-mail: gomg@bol.com.br

Telefone: (21) 3938-5262

\section{Rodrigo da Silva Santos Curvello}

Mestre em Ciências Contábeis pelo Programa de Pós-Graduação em Ciências Contábeis da UFRJ

Endereço: Av. Pasteur, 250 - sala 250, Urca

CEP: 22.290-250 - Rio de Janeiro/RJ- Brasil

E-mail: prof.rodrigocurvello@gmail.com

Telefone: (21) 3938-5262

\section{Jose Augusto Veiga da Costa Marques}

Doutor em Administração de Empresas pela EAESP/FGV

Professor do Programa de Pós-Graduação em Ciências Contábeis da UFRJ

Endereço: Av. Pasteur, 250 - sala 250, Urca

CEP: 22.290-250 - Rio de Janeiro/RJ- Brasil

E-mail joselaura@uol.com.br

Telefone: (21) 3938-5262

\section{Marcelo Alvaro da Silva Macedo}

Doutor em Engenharia da Produção pela UFRJ

Professor do Programa de Pós-Graduação em Ciências Contábeis da UFRJ

Endereço: Av. Pasteur, 250 - sala 250, Urca

CEP: 22.290-250 - Rio de Janeiro/RJ- Brasil

E-mail: malvaro@facc.ufrj.br

Tel (21) 3938-5262

Artigo recebido em 16/02/2016. Revisado por pares em 15/06/2016. Reformulado em 29/08/2016. Recomendado para publicação em 05/12/2016 por Carlos Eduardo Facin Lavarda (Editor-Chefe). Publicado em 17/12/2016. 


\title{
Resumo
}

O objetivo deste estudo é analisar a relação entre o gerenciamento tributário e algumas características empresariais do mercado segurador brasileiro. Para isso, foi realizada a análise bivariada para verificar se a effective tax rate (ETR) média das empresas do setor é distinta da nominal, e a análise multivariada, a fim de encontrar relações entre as variações da ETR e as seguintes características empresariais específicas: tamanho da firma, desempenho operacional e mix de ativos registrados. O processo de amostragem resultou em 543 (quinhentas e quarenta e três) observações no período de 2008 a 2013. As análises revelam indícios de que as empresas do mercado estudado praticam gerenciamento tributário, pois apresentam uma ETR média cerca de nove pontos percentuais menor do que a alíquota nominal aproximada de $40 \%$ prevista na legislação, e que a ETR possui relação negativa com tamanho, positiva com desempenho operacional e negativa com alguns componentes do ativo - participações societárias e ativos intangíveis.

Palavras-chave: Contabilidade tributária. Gerenciamento tributário. Effective Tax Rate (ETR). Mercado de seguros.

\begin{abstract}
This study aims to analyze the relation between tax management and insurance companies' characteristics. We apply two types of analysis: bivariate, analyzing whether the average of the effective tax rate (ETR) of companies in the sector differs than the nominal; and multivariate, to find evidence of relation between variations of ETR and some specific business characteristics: size, operating performance and mix of recorded assets. The sampling process resulted in 543 observations comprehended in 2008-2013. The analyses reveal that companies in the studied market in fact may be using tax management, since they have an average ETR of about nine percentage points lower than the approximate nominal rate of $40 \%$ established in the legislation. In addition, the ETR has an inverse relationship with size, a direct relationship with operating performance, and an inverse relationship with some asset components - equity investments and intangibles.
\end{abstract}

Keywords: Tax accounting. Tax management. Effective Tax Rate (ETR). Insurance market.

\section{Resumen}

El objetivo de este estudio es evaluar la relación entre la gestión tributaria en el mercado brasileño de seguros y algunas características empresariales. Se utilizan los análisis bivariado, para analizar si la tasa efectiva de impuestos (ETR) media de las empresas del sector es diferente que la nominal; y multivariado, a fin de encontrar evidencia de una relación entre las variaciones de la ETR y algunas características especificas del negocio. El procedimiento de muestreo resultó en 543 observaciones en el periodo 2008-2013. El análisis demuestra indicios de que las empresas en el mercado estudiado practican la gestión tributaria, puesto que tienen una ETR media cerca de nueve puntos porcentuales menor que la tasa nominal aproximada de 40\%, prevista en la legislación. Además, la ETR tiene relación negativa con el tamaño, positiva con el desempeño operacional y negativa con algunos de los componentes del activo - participaciones e intangibles.

Palabras clave: Contabilidad de impuestos. Gestión tributaria. Effective Tax Rate (ETR). Mercado de seguros. 


\section{Introdução}

A informação relativa aos tributos sobre o lucro presente nas demonstrações contábeis vem despertando o interesse de pesquisadores da área contábil, não obstante a pesquisa sobre tributação envolver campos de saberes distintos e ao mesmo tempo complementares, como a Economia, o Direito e a Contabilidade (HANLON; HEITZMAN, 2010; MAYDEW, 2001; SHACKELFORD; SHEVLIN, 2001).

De acordo com Graham, Raedy e Shackelford (2012), aprimorar o conhecimento acerca da contabilidade dos tributos sobre o lucro é importante, pois: (i) os tributos representam um custo comum e substancial a todas as companhias; (ii) essa contabilidade, além de gerar informações para investidores e credores, informa um terceiro interessado: a autoridade tributária; (iii) a informação dos tributos sobre o lucro fornece uma medida alternativa dos ganhos; e (iv) a relevância do custo tributário é notada inclusive pela apresentação destacada que recebe na demonstração de resultado.

Acrescente-se que a avaliação de empresas, nos seus variados modelos, não descarta o componente tributário na precificação, sendo relevante, portanto, estudar as características contábil-tributárias das empresas brasileiras. No campo da tributação brasileira sobre as pessoas jurídicas, destacam-se os tributos sobre o lucro: o imposto de renda da pessoa jurídica (IRPJ) e a contribuição social sobre o lucro líquido (CSLL).

A alíquota nominal estimada de tributação sobre o lucro das companhias do mercado segurador e das instituições financeiras é $6 \%$ maior do que os demais setores devido à majoração da alíquota da CSLL, totalizando cerca de 40\% - atualmente se encontra em 45\% devido à majoração da alíquota da CSLL de 15\% para 20\% (BRASIL, 2015). Esse custo tributário impacta o fluxo de caixa para a entidade e os acionistas, o que gera incentivos para um comportamento que busque reduzir esses tributos.

Além disso, o mercado segurador é formado majoritariamente por companhias organizadas sob a forma de sociedades por ações, fechadas e com estrutura acionária concentrada, que permanece em poder de grupos familiares, bancários e subsidiárias de empresas estrangeiras (MAYERS; SMITH, 1981; PROVIDENTE, 2015).

Essa estrutura de propriedade somada ao ciclo operacional invertido da operação de seguros e à necessidade de cumprimento de parâmetros de solvência pode incentivar a maximização de retornos atuais em detrimento de resultados futuros para o que favorece a redução dos custos tributários, sem maiores preocupações com os recursos que permanecerão na empresa.

Ainda, o gerenciamento tributário pode se tornar um incentivo para a prática do gerenciamento de resultados no mercado segurador, uma vez que as constituições e atualizações das provisões de sinistros registradas no passivo das seguradoras com reflexo direto no resultado contábil são dedutíveis para fins de apuração da base fiscal do IRPJ e da CSLL (BEAVER; MCNICHOLS; NELSON, 2003; GAVER; PATERSON, 1999; GRACE, 1990; NELSON, 2000; RODRIGUES, 2008). Por tudo isso, importa estudar o gerenciamento tributário nesse mercado.

O processo contábil é afetado por escolhas em processos decisórios nos quais o componente tributário não é irrelevante. Segundo Fields, Lys e Vincent (2001), a escolha contábil reside em processo de decisão no qual se busca influenciar a informação produzida tanto na forma quanto na substância, incluindo as informações reportadas ao fisco. O presente estudo procura evidências da presença de fatores relacionados às escolhas contábeis 
influenciadas pela questão tributária.

Ademais, Shackelford e Shevlin (2001) destacam a regulação como um elemento a ser considerado na pesquisa em contabilidade tributária. As indústrias reguladas possuem características úteis na comparação entre os livros fiscais e contábeis, tendo em vista que a regulação impõe evidenciação específica. No Brasil, as empresas de seguro - consideradas nesta pesquisa como o conjunto de sociedades seguradoras, entidades abertas de previdência complementar e resseguradores locais - devem cumprir as normas emanadas pelo Conselho Nacional de Seguros Privados (CNSP) e pela Superintendência de Seguros Privados (Susep) no que se refere à contabilização das respectivas operações.

Diante do exposto, este trabalho visa responder a seguinte questão de pesquisa: como as empresas de seguro se comportam frente à tributação sobre o lucro no que diz respeito ao gerenciamento tributário?

Assim, o objetivo central deste artigo é analisar a relação entre o gerenciamento tributário e algumas características empresariais do mercado segurador brasileiro. Como proxy do gerenciamento tributário utilizou-se a effective tax rate (ETR). A ETR é uma medida para o tax avoidance (HANLON; HEITZMAN, 2010), ou gerenciamento tributário, calculada a partir da divisão do custo com os tributos sobre o lucro pelo resultado antes dos tributos (LAIR). Considerou-se o gerenciamento tributário de forma abrangente, como Hanlon e Heitzman (2010) adotaram para conceituar tax avoidance: toda ação dos gestores da firma com o fim de minimizar os custos com tributos.

Frise-se que se busca explorar a contabilidade tributária do setor de seguros no Brasil pelos seguintes motivos: (i) levantamento de poucos estudos internacionais sobre o tema no mercado segurador, não tendo sido localizados estudos nacionais; (ii) oportunidade de conhecer o comportamento de gerenciamento tributário em companhias de capital fechado, pois o mercado estudado é quase totalmente formado por sociedades por ações sem ações negociadas em bolsa, mas com dados disponíveis devido à regulação praticada pelo Estado; (iii) existência de incentivos econômicos para a prática de um gerenciamento tributário agressivo devido à alíquota diferenciada de tributação sobre o lucro dessas empresas no Brasil, à possibilidade de maximização do resultado a partir da redução da taxa efetiva de tributos e ao surgimento de conflitos de interesses entre proprietários, gestores e segurados. Estes conflitos podem fazer com que proprietários e gestores desejem maximizar o resultado de períodos atuais em detrimento da capacidade de pagamento das obrigações futuras, o que pode ser obtido pela minimização dos custos com tributos.

Desse modo, a principal contribuição para a área é a observação do comportamento das empresas pertencentes a mercado altamente regulado como o de seguros, o qual ainda não foi analisado em relação às questões tributárias. Nesse sentido, a pesquisa contribui para a elevação do conhecimento acadêmico acerca das escolhas realizadas pelas companhias do mercado segurador que podem estar associadas aos respectivos níveis de gerenciamento tributário, para a avaliação dos participantes do mercado acerca dos custos de transação tributários decorrentes dessas escolhas e para a melhoria da regulação e do controle usados pelo Estado.

Foi realizado teste empírico da presença de gerenciamento tributário baseado na avaliação da ETR em empresas que compõem o mercado segurador brasileiro. Primeiramente, avaliou-se a aderência da alíquota efetiva frente à nominal. Depois, identificaram-se variáveis que pudessem explicar a variação da ETR no período de 2008 a 2013. Isso foi feito com a expectativa de se obter medidas capazes de capturar evidências do gerenciamento tributário

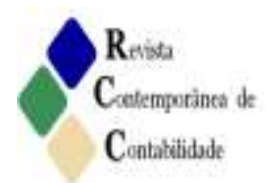


no mercado segurador. Ainda, uma análise de sensibilidade foi realizada inserindo uma variável dependente de prazo mais alongado (LongETR), construída a partir dos montantes acumulados de três exercícios não só dos resultados contábeis pré-tributos sobre o lucro, como também das despesas com IRPJ e CSLL. Nesse caso, o período utilizado foi de 2010 a 2013.

Por fim, é preciso ressaltar que a medição do custo efetivo dos tributos sobre o lucro, além de capturar indícios de gerenciamento, pode também indicar a presença de incentivos ou benefícios fiscais. Assim, alíquotas efetivas discrepantes da taxa nominal podem não estar associadas a práticas de gestão tributária. Outra ressalva a ser destacada é a impossibilidade de capturar reduções da taxa efetiva decorrentes de compensações de prejuízos, de modo que empresas com estoques de prejuízos fiscais apresentam alíquotas efetivas menores.

\section{Referencial Teórico}

\subsection{O Mercado Segurador Brasileiro}

$\mathrm{O}$ atual modelo institucional adotado no mercado de seguros brasileiro advém do Decreto-Lei n. 73/66. Segundo este documento, o Sistema Nacional de Seguros Privados (SNSP) é composto pelo Conselho Nacional de Seguros Privados (CNSP), pela Superintendência de Seguros Privados (Susep), pelos resseguradores, pelas sociedades autorizadas a operar em seguros privados e pelos corretores (BRASIL, 1966).

Nesse cenário, o CNSP é o órgão regulador do setor, responsável inclusive pela fixação das normas gerais de contabilidade e estatística a serem observadas pelas sociedades seguradoras, resseguradores, entidades abertas de previdência complementar e sociedades de capitalização, ou seja, pela regulação contábil e atuarial do mercado segurador brasileiro. Já a Susep é o órgão executivo, o qual responde pelas ações de fiscalização da execução das normas fixadas pelo CNSP.

Importa frisar que, por meio da Resolução n. 86/02, o CNSP possibilitou à Susep a atualização dos anexos da norma contábil, tarefa realizada anualmente com o objetivo de aprimorar o reconhecimento, a mensuração e a evidenciação das operações realizadas. Essa constante atualização também permite a continuidade do processo de convergência contábil do setor brasileiro de seguros aos padrões internacionais de contabilidade.

O processo de convergência da contabilidade aplicada a este mercado teve início tão logo foram emitidos os primeiros pronunciamentos técnicos pelo Comitê de Pronunciamentos Contábeis (CPC). O CPC foi criado em 2005 pelo Conselho Federal de Contabilidade (CFC), mas que iniciou a harmonização dos padrões emitidos pelo International Accounting Standard Board (IASB) ao contexto normativo brasileiro apenas em 2008, com a entrada em vigor da Lei n. 11.638/07, marco legal da convergência.

Nesse sentido, desde 2008 a Susep vem recepcionando as normas emitidas pelo CPC em conformidade com o estabelecido no art. 10-A da Lei n. 6.385/76. As Circulares Susep n. $356 / 07$ e n. 375/08 recepcionaram as regras internacionais sobre a redução ao valor recuperável de ativos e a demonstração dos fluxos de caixa (DFC), mas foi a Circular Susep n. 379/08 que recepcionou a maior parte dos pronunciamentos da primeira fase da convergência: desde a Estrutura Conceitual até o pronunciamento sobre a adoção inicial da Lei n. 11.638/07 e da Medida Provisória n. 449/08 (CPC 13). Frise-se que o CPC 11 sobre contratos de seguros só passou a ser exigido no exercício de 2011.

A segunda fase da convergência no mercado segurador ocorreu no exercício de 2011 
com a edição da Circular Susep n. 424/11, que recepcionou diversas normas relevantes ao mercado segurador emitidas até aquele momento, como as relacionadas aos contratos de seguros; provisões, passivos contingentes e ativos contingentes; apresentação das demonstrações contábeis; tributos sobre o lucro; benefícios a empregados; reconhecimento, mensuração, apresentação e evidenciação de instrumentos financeiros, entre outros. Por fim, a Circular Susep n. 483/14 recepcionou normas sobre divulgação de participações em outras entidades e mensuração do valor justo, passando a exigi-las a partir de 2014. Essas Circulares também recepcionaram algumas Interpretações Técnicas emitidas pelo CPC.

Conforme se verifica, a maioria das recepções ocorreu a partir do ano de 2011 e na atualidade praticamente todos os Pronunciamentos aplicáveis ao mercado encontram-se recepcionados, passando a fazer parte do rol de normas exigidas pelo regulador (enforcement). No entanto, em alguns casos foram feitas ressalvas ao padrão originalmente emitido com a finalidade de resguardar a solvência do mercado. Isso porque hoje as demonstrações contábeis individuais são usadas como base para o acompanhamento de alguns parâmetros de solvência das empresas de seguro, entre eles a suficiência de capital em relação aos montantes requeridos com base nas respectivas exposições de riscos (MELO; NEVES, 2012).

O mercado segurador diferencia-se dos demais por apresentar um ciclo operacional invertido. Nas operações mercantis e de prestação de serviços, em geral o vendedor primeiro incorre em custos necessários à produção e entrega do bem/serviço e só em seguida, como consequência da venda do bem produzido ou serviço prestado, obtém os benefícios econômicos da transação; as receitas tornam-se ganhas e o caixa é ou será afetado positivamente. No entanto, as empresas de seguro recebem antecipadamente o prêmio de forma a garantir o pagamento da importância contratada pelo segurado durante o prazo de cobertura do risco assumido nos casos de ocorrência de sinistro (CONTADOR, 2007). Dessa forma, as empresas de seguro acumulam recursos financeiros expressivos, o que impõe ao mercado uma necessidade de regras específicas como a constituição de provisões técnicas e uma regulação forte que garanta a solvência futura das empresas.

O modelo de fiscalização à distância adotado pela Susep leva em consideração pelo menos quatro fatores: a adequação das provisões técnicas constituídas, a suficiência dos ativos que garantem essas provisões técnicas, a suficiência do Patrimônio Líquido frente ao Capital Mínimo Requerido e indicadores econômico-financeiros (BRASIL, 2015).

Importa aqui lembrar que as provisões técnicas são totalmente dedutíveis para efeito de apuração do lucro real e da base de cálculo da CSLL (BRASIL, 1999). No entanto, esse aparente incentivo pode levar as seguradoras a piorar seus parâmetros de solvência, uma vez que os accruals resultantes da constituição ou complementos afetam negativamente o resultado, gerando menores montantes a serem transferidos ao patrimônio líquido, que, por sua vez, é a base para o cálculo do Patrimônio Líquido Ajustado usado na medição das exigências de capital deste mercado.

Em última análise, acredita-se que as empresas interessadas em gerenciar suas provisões de sinistros com fins tributários estariam antes com níveis folgados do parâmetro de solvência relacionado à exigência de capital. Ademais, o acréscimo das provisões de sinistro leva ao aumento do volume de ativos garantidores desses passivos, o que sugere que as companhias novamente terão de fazer uma escolha entre pagar menos tributos ou arcar com os custos de cumprir os parâmetros de solvência.

Quantos aos indicadores econômico-financeiros, cumpre destacar 3 (três) para este

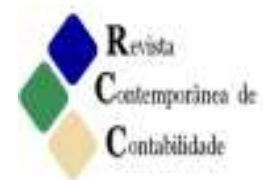


trabalho: o índice de sinistralidade, o índice combinado e o índice combinado ampliado. Todos são medidas de desempenho específicas do mercado segurador, internacionalmente conhecidas e obtidas a partir de saldos das contas apresentadas na Demonstração do Resultado do Exercício (DRE).

Para Silva (1999), o índice de sinistralidade (ISN) mede comparativamente a despesa de sinistros com a receita líquida de prêmio, por meio da divisão entre esses fatores. Considerando a atual configuração da demonstração do resultado constante do Anexo III da Circular Susep n. 508/15, o indicador resulta da divisão da soma de sinistros ocorridos e despesas com benefícios pela soma das contas de prêmios ganhos e receitas de contribuições, receita com emissão de apólices, receitas de contribuições e prêmios de VGBL, rendas com taxas de gestão e outras taxas e variação de outras provisões técnicas.

Silva (1999) esclarece que o índice combinado (IC) expressa o resultado das operações básicas de seguro, relacionando receitas e despesas exclusivamente operacionais do mercado segurador. Assim, no contexto atual o IC é calculado pela divisão da soma das contas de sinistros ocorridos, despesas com benefícios, custos de aquisição, resultado com resseguros ou resultado com retrocessão (no caso dos resseguradores), outras receitas e despesas operacionais, despesas administrativas e despesas com tributos, pela soma das contas de prêmios ganhos e receitas de contribuições, receita com emissão de apólices, receitas de contribuições e prêmios de VGBL, rendas com taxas de gestão e outras taxas e variação de outras provisões técnicas. Companhias com resultados maiores do que 1 encontram-se em desequilíbrio operacional, que ainda pode ser revertido com o resultado financeiro obtido das aplicações financeiras realizadas, operação volumosa neste mercado devido à característica de acumulação de fundos da operação e às altas taxas de juros encontradas no mercado brasileiro.

Nesse sentido, o IC pode ser modificado para considerar o resultado financeiro, que no cenário brasileiro pode ser bastante relevante para as empresas devido ao esclarecido anteriormente. Chama-se esse indicador modificado de Índice Combinado Ampliado (ICA), em que o Resultado Financeiro passa a ser considerado no denominador em conjunto com os Prêmios Ganhos (SILVA, 1999).

As Fórmulas 1, 2 e 3 resumem as descrições dos indicadores ISN, IC e ICA:

$$
\begin{aligned}
\mathrm{ISN} & =\frac{\mathrm{SO}+\mathrm{DB}}{\mathrm{PG}+\mathrm{REA}+\mathrm{RCPVGBL}+\mathrm{RTG}+\mathrm{VOPT}} \\
\mathrm{IC} & =\frac{\mathrm{SO}+\mathrm{DB}+\mathrm{CA}+\mathrm{RR}+\mathrm{ORDO}+\mathrm{DA}+\mathrm{DT}}{\mathrm{PG}+\mathrm{REA}+\mathrm{RCPVGBL}+\mathrm{RTG}+\mathrm{VOPT}} \\
\mathrm{ICA} & =\frac{\mathrm{SO}+\mathrm{DB}+\mathrm{CA}+\mathrm{RR}+\mathrm{ORDO}+\mathrm{DA}+\mathrm{DT}}{\mathrm{PG}+\mathrm{REA}+\mathrm{RCPVGBL}+\mathrm{RTG}+\mathrm{VOPT}+\mathrm{RF}}
\end{aligned}
$$

em que: $\mathrm{SO}=$ sinistros ocorridos; $\mathrm{DB}=$ despesas com benefícios; $\mathrm{CA}=$ custos de aquisição; $\mathrm{RR}=$ resultado com resseguro ou resultado com retrocessão (no caso de resseguradores); ORDO = outras receitas e despesas operacionais; DA $=$ despesas administrativas; $\mathrm{DT}=$ despesas com tributos; $\mathrm{PG}=$ prêmios ganhos e receitas de contribuições; REA = receita com emissão de apólices; $\mathrm{RCPVGBL}=$ receitas de contribuições e prêmios de VGBL; RTG = rendas com taxas de gestão e outras taxas; VOPT 
= variação de outras provisões técnicas; e $\mathrm{RF}=$ resultado financeiro.

Quanto à tributação do mercado segurador, o IRPJ incide sobre o lucro líquido ajustado à alíquota de $15 \%$ mais $10 \%$ sobre a parcela mensal que exceder a 20.000 reais (240.000 reais anuais). Neste trabalho será considerada a alíquota de $25 \%$ para IRPJ, dado o caráter imaterial da diferença entre esta e a calculada de forma exata para a amostra avaliada. Já a CSLL incide sobre a alíquota majorada de 15\% (BRASIL, 1988, 1999).

Ainda, a legislação tributária permite que as provisões técnicas constituídas pelas seguradoras sejam deduzidas na apuração do lucro tributável (BRASIL, 1999). Com isso, gestores podem usar da discricionariedade inerente à mensuração inicial e subsequente das provisões de sinistros para reduzir o pagamento de tributos sobre o lucro, assim como encontrado por Beaver, McNichols e Nelson (2003), Gaver e Paterson (1999), Grace (1990), Nelson (2000) e Rodrigues (2008), o que se espera capturar com o índice de sinistralidade (ISN).

\subsection{Gerenciamento Tributário}

Os efeitos das imposições da lei tributária incidentes sobre os resultados das empresas têm sido objeto de pesquisa em contabilidade. Conforme Maydew (2001), a pesquisa em tributação é interdisciplinar, sendo elaborada por economistas, contadores e por financistas. Entretanto, contadores teriam uma vantagem comparativa sobre os demais por desenvolver maior conhecimento empírico das estratégias tributárias e da contabilidade financeira.

Shackelford e Shevlin (2001) exploraram em ensaio teórico as pesquisas em tributação descrevendo o avanço da pesquisa empírica em contabilidade tributária de quinze anos. A partir do modelo paradigma de Sholes e Wolfson (1990) (todas as partes, todos os impostos e todos os custos), os autores identificam e detalham as 3 (três) maiores linhas de pesquisa desenvolvidas: i) a coordenação de fatores tributários e não tributários; ii) o efeito dos impostos sobre o preço dos ativos; e iii) a tributação do comércio internacional (ou interestadual). De acordo com o texto, ao se avaliar um efetivo planejamento fiscal não se tem como alvo a simples redução dos tributos, mas todo um desenho organizacional sob a perspectiva contratual. Nessa perspectiva avaliam-se todas as partes contratuais, todos os impostos (explícitos ou implícitos) e todos os custos não tributários envolvidos. Ressalte-se, no estudo dos fatores tributários e não tributários, o destaque dado pelos autores à regulação como um elemento a ser considerado na pesquisa em contabilidade tributária. As indústrias reguladas possuem características úteis na comparação entre os livros fiscais e contábeis tendo em vista a regulação impor evidenciação específica. Os autores indicam ainda que a ETR é uma boa medida para o gerenciamento tributário: quanto mais baixa, mais adequado o planejamento.

Segundo Tang (2005), as empresas incorrem em práticas de gerenciamento dos tributos para maximizar o retorno dos acionistas, reduzir o risco de controle fiscal e custo político, estabelecer os parâmetros de compensação dos gerentes após os impostos e atender às expectativas do mercado, uma vez que os tributos sobre o lucro consistem em fatores determinantes na precificação dos ativos. A autora, que pesquisou evidências empíricas da relação entre gerenciamento de resultados e gerenciamento tributário no mercado chinês, pontua que as firmas procuram reduzir os custos com tributos em países com carga tributária elevada.

Em relação ao tax avoidance, Desai e Dharmapala (2009) o consideram como

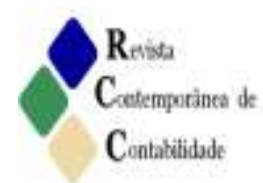


consequência do conflito entre principal e agente: a redução do custo com tributos é perseguida pelos executivos quando estes são incentivados ou compensados financeiramente pelos acionistas que desejam aumentar o lucro do negócio.

Hanlon e Heitzman (2010) definem o termo em sentido amplo, como uma redução das taxas explícitas. A partir de pesquisas anteriores, as autoras listam 12 (doze) diferentes medidas utilizadas para capturar o gerenciamento tributário. Entre essas medidas destacam-se aqui as relativas à alíquota efetiva, ou seja, a ETR, calculada a partir da despesa total com os tributos dividida pelo resultado antes dos impostos e a CurrentETR, obtida pela razão entre o encargo corrente com os tributos e o resultado antes dos tributos. Há ainda uma medida que captura o efeito da alíquota efetiva no longo prazo, a CashETR, calculada pela divisão da soma dos tributos pagos nos últimos dez anos pela soma dos resultados antes dos tributos no mesmo prazo. Outra medida de destaque é a Book-tax diference (BTD), diferença entre o lucro antes dos tributos e a base tributável estimada pela razão entre o encargo corrente com os tributos dividida pela alíquota nominal.

Ao explorar o conceito de agressividade tributária, Chen et al. (2010) esclarecem que são ações que visam à redução do lucro tributável. Da mesma forma que Hanlon e Heitzman (2010) consideram que o termo tem acepção ampla: engloba desde planejamentos legais, passando por aquelas estruturas localizadas em áreas cinzentas, até às práticas evasivas. Defendem também que os temos tax avoidance ou tax management (gerenciamento tributário) tem o mesmo significado.

Stickney e McGee (1982) pesquisaram o comportamento da alíquota efetiva de impostos (ETR) nas maiores empresas americanas, procurando encontrar relações entre esta e o tamanho da empresa, o uso de capital intensivo e o grau de alavancagem. Concluíram que a combinação de grandes investimentos de capital e de alavancagem resultam em menores taxas efetivas.

Gupta e Newberry (1997) testaram a ETR utilizando modelo em painel em uma amostra balanceada de empresas americanas e procuraram relacionar a variável dependente com o tamanho das empresas, estrutura de capital (alavancagem), retorno (performance) e com um mix de ativos: imobilizados, estoques e gastos com pesquisa e desenvolvimento. $\mathrm{O}$ pressuposto é que empresas intensivas em imobilizado, dado os benefícios fiscais associados (como a depreciação), apresentariam uma relação negativa com a ETR. Já as empresas com maior participação de estoques na composição dos recursos apresentariam uma ETR positiva. Em relação aos gastos com pesquisa e desenvolvimento, a relação com a ETR seria negativa. A variável explicativa ROA (rentabilidade) também foi acrescida como controle. Nesse modelo, baseado nas características econômicas da firma, os autores conseguiram explicar de $38 \%$ a $48 \%$ da variação da ETR. Conforme os resultados, quanto maior a empresa ou o grau de alavancagem, menor a ETR observada. Acerca dos componentes do ativo, demonstraram que empresas com maiores percentuais de ativos fixos apresentam ETR menor, enquanto que empresas com grandes percentuais de estoques apresentam uma ETR maior. A rentabilidade medida pelo ROA mostrou-se significativa e positiva.

Mills, Newberry e Trautman (2002) compararam dados agregados de demonstrações financeiras com declarações ao fisco de empresas americanas, com o objetivo de explorar as diferenças entre o resultado contábil e a base tributável (BTD). Os autores observaram que a BTD aumentou consideravelmente ao longo do período de 1991 a 1998. Constataram que as diferenças são mais intensas em empresas multinacionais, de setores de serviços financeiros e da indústria de comunicação, bem como em empresas com maior lucratividade, sugerindo 
menores ETRs para essas companhias.

Rego (2003) testou a ETR de empresas multinacionais em relação ao tamanho da empresa, ao resultado antes dos impostos (performance) e às operações no exterior. A autora ressalta que em relação ao tamanho da firma há resultados divergentes decorrentes de duas correntes teóricas. Para determinada linha de pensamento, empresas de maior porte conseguem influenciar politicamente no processo tributário, organizando suas atividades numa forma ótima de economia de impostos. Já outros autores advogam pela hipótese do custo político: empresas maiores estão sob vigilância dos órgãos governamentais e apresentam uma maior carga fiscal relativa. Os resultados da pesquisa apontam para uma ETR com o mesmo sinal do tamanho, o que vai ao encontro da hipótese do custo político. Em relação à performance, o resultado encontrado foi que empresas com melhor desempenho apresentam ETRs menores.

Richardson e Lanis (2007), ao estudar os efeitos da alteração da legislação tributária na Austrália, mediram a ETR e aplicaram o modelo de regressão linear, considerando como determinantes o tamanho da empresa, a estrutura de capital, os elementos componentes do ativo (grau de imobilização e de estoques) e os gastos com pesquisa e desenvolvimento. Esses elementos foram inseridos para avaliar a alteração legislativa naquele país. Os autores mediram também como controle a rentabilidade do ativo. Os resultados indicaram que o tamanho da firma apresenta relação significativa e negativa com a ETR, assim como para a alavancagem. Já a rentabilidade também se mostrou significativa, porém positiva. $O$ imobilizado apresentou forte significância estatística com sinal negativo e o estoque também foi significativo, mas com sinal positivo.

No Brasil, Gomes (2012) avaliou o gerenciamento tributário em empresas brasileiras de capital aberto, no período de 2001 a 2010, pelo comportamento das seguintes proxies: ETR, CashETR e BTD. A pesquisa também procurou testar se as características de governança corporativa (remuneração da diretoria, tamanho do Conselho de Administração, segregação entre Chairman e CEO e independência do Conselho de Administração) influenciavam o gerenciamento tributário das empresas brasileiras com ações negociadas na Bolsa de Valores, Mercadorias e Futuros de São Paulo (BMF\&Bovespa). Por meio da análise de dados em painel somente foi confirmada a hipótese em relação à variável de remuneração da diretoria executiva.

Cabello (2012) estudou a ETR a partir da teoria das escolhas contábeis que deriva da teoria contratual da firma. No trabalho foram analisadas as notas explicativas das demonstrações financeiras de companhias abertas no período de 2009 a 2010 . Os testes foram realizados a partir de uma amostra de 250 empresas em 2009 e 272 empresas em 2010. Foi observado que empresas que adotaram depreciação acelerada, depreciação acelerada incentivada, juros sobre o capital próprio, reorganização societária e incentivos fiscais apresentaram em média uma ETR menor. O porte da empresa também se mostrou significativo para efeito da ETR, o que corrobora pesquisas anteriores.

O Quadro 1 resume alguns dos achados encontrados nas pesquisas anteriores em relação às características das companhias que praticam gerenciamento tributário.

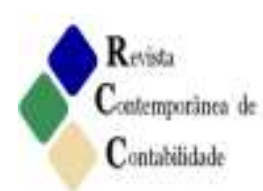


Guilherme Otávio Monteiro Guimarães, Rodrigo da Silva Santos Curvello, José Augusto Veiga da Costa Marques, Marcelo Alvaro da Silva Macedo

\begin{tabular}{|c|c|c|c|}
\hline \multicolumn{4}{|c|}{$\begin{array}{c}\text { Quadro } 1 \text { - Principais achados sobre as características empresariais associadas à redução da carga } \\
\text { tributária }\end{array}$} \\
\hline $\begin{array}{l}\text { Autor } \\
\text { (ano) }\end{array}$ & $\begin{array}{l}\text { Amostra } \\
\text { (país) }\end{array}$ & $\begin{array}{c}\text { Variável } \\
\text { dependente }\end{array}$ & Principais achados (sinal do coeficiente) \\
\hline $\begin{array}{l}\text { Stickney e McGee } \\
\quad(1982)\end{array}$ & $\begin{array}{l}\text { maiores empresas } \\
\text { americanas }\end{array}$ & ETR & $\begin{array}{l}\text { tamanho (-); capital intensivo (-) } \\
\text { grau de alavancagem }(-)\end{array}$ \\
\hline $\begin{array}{l}\text { Gupta \& Newberry } \\
\text { (1997) }\end{array}$ & $\begin{array}{l}\text { empresas } \\
\text { americanas }\end{array}$ & ETR & $\begin{array}{c}\text { tamanho (-); estrutura de capital - alavancagem (-); } \\
\text { imobilizado (-); estoque }(+) \text {; gastos com P\&D (-); } \\
\text { rentabilidade (ROA) }(+)\end{array}$ \\
\hline $\begin{array}{l}\text { Mills, Newberry e } \\
\text { Trautman (2002) }\end{array}$ & $\begin{array}{l}\text { empresas } \\
\text { americanas }\end{array}$ & BTD & $\begin{array}{c}\text { Multinacionais }(+) \text {, setores de serviços financeiros } \\
\text { e da indústria de comunicação }(+) \text { e empresas com } \\
\text { maior lucratividade }(+)\end{array}$ \\
\hline $\begin{array}{l}\text { Rego } \\
(2003)\end{array}$ & $\begin{array}{l}\text { empresas } \\
\text { multinacionais } \\
\text { americanas }\end{array}$ & ETR & $\begin{array}{c}\text { tamanho da empresa }(+) \text {; LAIR (performance) }(-) ; \\
\text { operações no exterior }(-)\end{array}$ \\
\hline $\begin{array}{l}\text { Richardson e Lanis } \\
\qquad(2007)\end{array}$ & $\begin{array}{l}\text { empresas na } \\
\text { Austrália }\end{array}$ & ETR & $\begin{array}{l}\text { tamanho da empresa (-); estrutura de capital (-) } \\
\text { grau de imobilização }(-) \text {; estoques }(+) \\
\text { gastos com P\&D (-); rentabilidade }(+)\end{array}$ \\
\hline Gomes (2012) & $\begin{array}{l}\text { empresas abertas } \\
\text { brasileiras }\end{array}$ & $\begin{array}{l}\text { ETR, BTD } \\
\text { e CashETR }\end{array}$ & remuneração variável da diretoria executiva (-) \\
\hline $\begin{array}{l}\text { Cabello } \\
(2012)\end{array}$ & $\begin{array}{l}\text { empresas abertas } \\
\text { brasileiras }\end{array}$ & ETR & $\begin{array}{c}\text { depreciação acelerada (-); depreciação acelerada } \\
\text { incentivada (-); juros sobre o capital próprio (-); } \\
\text { reorganização societária (-); tamanho (-); } \\
\text { incentivos fiscais (-) }\end{array}$ \\
\hline
\end{tabular}

Fonte: Os autores, 2015.

\section{Metodologia da Pesquisa}

Conforme seus objetivos, esta pesquisa pode ser considerada descritiva e explicativa, já que busca descrever as características da alíquota efetiva de tributos sobre o lucro das companhias do mercado segurador brasileiro, bem como explicar o motivo de suas variações, esclarecendo quais fatores contribuem para o gerenciamento tributário (SILVA, 2010). Além disso, utilizou-se a abordagem positivista empírico-analítica, em que são perseguidas evidências empíricas dos efeitos do gerenciamento tributário no mercado estudado, com estabelecimento de relações entre a ETR e possíveis características empresariais encontradas na literatura. Para isso, coletaram-se dados para tratamento e posterior análise quantitativa, com validação por meio de testes dos instrumentos estatísticos utilizados e níveis de significância (ZANCHET; MARQUES; MARTINS, 2011).

$O$ processo de amostragem é não probabilístico e intencional, realizado a partir do universo limitado de companhias participantes do mercado segurador brasileiro. Foram excluídas intencionalmente: (i) as sociedades de capitalização, pelas características peculiares de suas operações; (ii) as entidades abertas de previdência complementar sem fins lucrativos, por não sofrerem a tributação sobre o lucro; (iii) as empresas cuja soma das receitas líquidas de seguros, resseguros e previdência - somatório das contas de resultado de prêmios ganhos e 
receitas de contribuições, receita com emissão de apólices, receitas de contribuições e prêmios de VGBL, rendas com taxas de gestão e outras taxas e variação de outras provisões técnicas foi menor ou igual a zero nos períodos analisados, devido à utilização deste fator como denominador de variáveis utilizadas no estudo; (iv) companhias com resultado negativo antes dos impostos e participações e/ou com despesa de IR/CSLL menor ou igual a zero, devido ao menor incentivo dessas companhias para o gerenciamento tributário e à operacionalização da variável dependente; e (v) as observações outliers, consideradas assim quando a variável ETR foi inferior ao limite do primeiro quartil diminuído de uma vez e meia o intervalo interquartílico ou superior ao terceiro quartil somado a uma vez e meia o intervalo interquartílico (FÁVERO et al., 2009).

A amostra final contém 543 (quinhentas e quarenta e três) observações envolvendo os anos de 2008 a 2013, período escolhido por abranger desde a recepção dos primeiros padrões internacionais de contabilidade no mercado segurador brasileiro até o último exercício com demonstrações contábeis divulgadas na data em que o sítio eletrônico da Susep foi consultado para realização da pesquisa, qual seja, 28/02/2015. A Tabela 1 apresenta a quantidade de observações em cada ano do estudo.

Tabela 1 - Processo de amostragem com observações por ano

\begin{tabular}{llccccccc}
\hline \multirow{2}{*}{ Etapas do Processo de Amos tragem } & \multicolumn{7}{c}{ Exercícios Sociais Analis ados } \\
\cline { 2 - 9 } & $\mathbf{2 0 0 8}$ & $\mathbf{2 0 0 9}$ & $\mathbf{2 0 1 0}$ & $\mathbf{2 0 1 1}$ & $\mathbf{2 0 1 2}$ & $\mathbf{2 0 1 3}$ & Total \\
\hline Companhias autorizadas em 31/dez & 170 & 162 & 164 & 169 & 174 & 176 & $\mathbf{1 0 1 5}$ \\
\hline$(-)$ & Sociedades de capitalização & -17 & -15 & -16 & -19 & -18 & -19 & $\mathbf{- 1 0 4}$ \\
\hline$(-)$ & EAPCs sem fins lucrativos & -23 & -23 & -21 & -20 & -20 & -20 & $\mathbf{- 1 2 7}$ \\
\hline$(-)$ Companhias com receita de seguros $\leq 0$ & -11 & -7 & -8 & -10 & -10 & -8 & $\mathbf{- 5 4}$ \\
\hline$(-)$ & Companhias com LAIR $\leq 0$ & -23 & -12 & -6 & -15 & -27 & -40 & $-\mathbf{- 1 2 3}$ \\
\hline$(-)$ & Companhias com IRPJ + CSLL $\leq 0$ & -11 & -8 & -4 & -2 & -3 & -7 & $\mathbf{- 3 5}$ \\
\hline$(-)$ Outliers & -4 & -6 & -7 & -7 & -3 & -2 & $\mathbf{- 2 9}$ \\
\hline$(=)$ Total de companhias da amostra & $\mathbf{8 1}$ & $\mathbf{9 1}$ & $\mathbf{1 0 2}$ & $\mathbf{9 6}$ & $\mathbf{9 3}$ & $\mathbf{8 0}$ & $\mathbf{5 4 3}$ \\
\hline
\end{tabular}

Fonte: Os autores, 2015.

Os testes foram realizados com os dados em pooled não havendo controle temporal nas regressões, o que faz com que não seja necessário balancear as observações por ano.

Considerando os objetivos desta pesquisa, foram coletados os dados econômicofinanceiros disponíveis no Sistema de Estatísticas da Susep (SES), no site da Autarquia (www.susep.gov.br), com uso da opção "Seguradoras: Demonstrações Contábeis" (SES) e filtros buscando as empresas da amostra e os meses de dezembro de cada um dos anos pesquisados. Em que pese a base da Susep forneça dados mensais, a ETR, variável a ser explicada neste estudo, só é conhecida pela companhia ao final do exercício. Ademais, importa frisar que a escolha da variável ETR como única proxy para o gerenciamento tributário deve-se à ausência de abertura no SES das contas de despesa com tributos sobre o lucro. O cálculo da CashETR e da BTD dependem do conhecimento das despesas correntes e diferidas dos tributos sobre o lucro, o que não está disponível nesta base de dados.

A seguir são desenvolvidas 6 (seis) hipóteses baseadas nos objetivos deste estudo e na literatura prévia. Segundo Shackelford e Shevlin (2001), as empresas que praticam um gerenciamento tributário eficaz apresentam alíquotas efetivas reduzidas. Ademais, a elevada carga tributária de alguns países caracteriza-se como um incentivo ao gerenciamento 
tributário (TANG, 2005), sendo este o caso do mercado segurador brasileiro. Estima-se que as empresas do mercado segurador tenham incentivos para realizar escolhas contábeis que minimizem a carga de tributos sobre o lucro. Assim, formulou-se a seguinte hipótese:

H1: A média da ETR da amostra é inferior à alíquota nominal aproximada de IR e CSLL (40\%).

Acerca dos determinantes do gerenciamento tributário, foram formuladas 6 (seis) hipóteses de relacionamento com a variável dependente ETR. Gupta e Newberry (1997), Richardson e Lanis (2007) e Stickney e McGee (1982) encontraram evidências de que as maiores empresas possuem os recursos necessários para reduzir a carga efetiva. Mills, Newberry e Trautman (2002) identificaram maiores níveis de BTD em multinacionais. Em sentido inverso, Rego (2003) observou que empresas de maior porte apresentam maiores índices de alíquota efetiva de tributos sobre o lucro, o que confere suporte à suposição do custo político. Não obstante os resultados encontrados por Rego (2003), considerando as evidências das demais pesquisas, estima-se que as seguradoras de maior porte apresentem menor ETR. Assim, espera-se detectar relação negativa entre a ETR e o tamanho da firma:

$\mathbf{H}_{2}$ : Há relação inversa entre a ETR e o tamanho das empresas de seguro, de modo que empresas maiores tendem a apresentar menores alíquotas efetivas de tributos sobre o lucro.

Gupta e Newberry (1997) e Richardson e Lanis (2007) observaram uma relação positiva entre a rentabilidade da firma e a alíquota efetiva de tributos. Empresas com maiores ganhos teriam naturalmente maiores tributos, pois a ETR seria uma função da divisão das preferências (ajustes) fiscais pelo resultado contábil. Considerando que estes fatores não são proporcionais, uma mudança no resultado contábil pode resultar em alteração da ETR, fazendo com que seja necessário controlar as variações no resultado contábil para uma correta análise da influência das características da empresa (por exemplo, maior tamanho) sobre a ETR.

No mercado segurador, o desempenho operacional da companhia pode ser avaliado a partir do uso de vários indicadores, entre eles o ICA, o IC e o ISN, sendo o ICA o mais abrangente por considerar todas as receitas e despesas da operação de seguros e ainda o resultado financeiro (em regra positivo) e o ISN o mais específico, posto que mede o desempenho apenas em relação aos sinistros ocorridos. Tais indicadores devem ser interpretados de forma cautelosa, pois ao contrário dos indicadores tradicionais, maiores valores significam piora de rendimento operacional passando ao desequilíbrio, no caso do ICA e do IC, quando ultrapassam o valor 1 . Em outras palavras, quando, para cada $\mathrm{R} \$ 1,00$ de receita proveniente das operações de seguros, resseguros e previdência, tem-se mais do que R \$1,00 de despesas respectivas. Já a avaliação do ISN dependerá dos ramos de atuação da companhia, não sendo necessário ultrapassar o valor 1 para ser considerado alto.

Nesse sentido, ICA, IC e ISN foram utilizados com o objetivo de verificar se o desempenho operacional (performance) está relacionado com menores alíquotas efetivas de tributos sobre o lucro, assim como encontraram Mills, Newberry e Trautman (2002) e Rego (2003). Esses indicadores são compostos por elementos que se encontram no âmbito do julgamento dos profissionais de contabilidade e de atuária quando do reconhecimento e mensuração contábeis, tornando-se possíveis mecanismos de gerenciamento tributário. É o caso dos sinistros, em que a discricionariedade inerente da mensuração tem sido objeto de diversos estudos nacionais e internacionais acerca do gerenciamento de resultados com finalidades diversas que incluem a redução de despesas com tributos (BEAVER; MCNICHOLS; NELSON, 2003; GAVER; PATERSON, 1999, 2004; GRACE, 1990; 
GRACE; LEVERTY, 2012; NELSON, 2000; PETRONI, 1992; RODRIGUES, 2008). Nesse sentido, espera-se uma relação significativa e com sinal negativo da ETR com ICA, IC e ISN.

H3: Há relação direta entre a ETR e o desempenho das empresas de seguro medido pelos indicadores ICA $\left(\mathrm{H}_{3 \mathrm{a}}\right)$, IC $\left(\mathrm{H}_{3 \mathrm{~b}}\right)$ e ISN $\left(\mathrm{H}_{3 \mathrm{c}}\right)$, de modo que empresas com menores níveis desses indicadores tendem a maiores alíquotas efetivas.

Gupta e Newberry (1997), Richardson e Lanis (2007) e Stickney e McGee (1982) encontraram relações entre ETR e determinado mix de ativos, entre eles imobilizado e estoques. No caso do imobilizado os autores estimaram e encontraram uma relação negativa com a ETR decorrente provavelmente dos incentivos associados às despesas com depreciação. De outro turno, os estudos apontam para uma relação positiva entre a ETR e os estoques. $\mathrm{Na}$ atividade desenvolvida pelas sociedades seguradoras, entidades de previdência ou resseguradores, o imobilizado não se apresenta como conta relevante do ativo e não há aplicação de recursos em estoques. Entretanto, ao negociar as apólices, planos de previdência ou contratos de resseguros, são acumulados gastos de aquisição no ativo, como por exemplo, comissões de corretagem, que são realizados ao longo da vigência da apólice a que se relacionam, em conformidade com o princípio da competência. Nesse sentido, espera-se encontrar uma relação positiva entre a ETR e esses custos de aquisição diferidos (DAC): empresas.

H4: Há relação direta entre a ETR e o nível de custos de aquisição diferidos das

Cabello (2012) demonstrou que a ETR é impactada por determinadas escolhas contábeis. Um dos fatores a influenciar a redução da alíquota efetiva seriam os processos de reorganização societária, tendo em vista as repercussões fiscais da utilização do ágio por rentabilidade futura. Gomes (2012) identificou a amortização do ágio como um dos principais responsáveis pela redução do custo com os tributos sobre o lucro. A Lei n. 9.532/97 permitiu a dedutibilidade fiscal do ágio fundamentado na rentabilidade futura de controlada ou coligada, quando ocorresse evento de incorporação, fusão ou cisão. A partir de 2008, com a observância dos novos padrões contábeis, a diferença entre o valor pago pela aquisição de investimentos e o valor do patrimônio líquido passou a ser segregada em mais-valia e goodwill. Observe-se que o goodwill é evidenciado nos intangíveis nas demonstrações contábeis consolidadas. Entretanto, não houve alteração do benefício fiscal da amortização do ágio no período estudado. Empresas de seguro que detinham participações societárias com ágio poderiam reduzir o custo com os tributos sobre o lucro a partir de reorganizações societárias. Nessa linha, procura-se capturar os efeitos da amortização do ágio. Empresas seguradoras com registros de mais-valia ou goodwill podem ter se utilizado do benefício de amortização do ágio previsto na legislação tributária; estima-se, portanto, que entidades com níveis maiores de intangíveis e de participações societárias apresentem uma ETR menor:

H5: Há relação inversa entre a ETR e o nível de ativos intangíveis das empresas.

H6: Há relação inversa entre a ETR e o nível de investimentos em participações societárias das empresas.

Dessa forma, os seguintes modelos foram construídos com o objetivo de testar as hipóteses $\mathrm{H}_{2}$ a $\mathrm{H}_{6}$ desenvolvidas:

$$
\begin{aligned}
& E T R_{i t}=\beta_{0}+\beta_{1} L N A T_{i t}+\beta_{2} I C A_{i t}+\beta_{3} D A C_{i t}+\beta_{4} I N T_{i t}+\beta_{5} I N V_{i t}+\varepsilon_{i t} \\
& E T R_{i t}=\beta_{0}+\beta_{1} L N A T_{i t}+\beta_{2} I C_{i t}+\beta_{3} D A C_{i t}+\beta_{4} I N T_{i t}+\beta_{5} I N V_{i t}+\varepsilon_{i t}
\end{aligned}
$$




$$
E T R_{i t}=\beta_{0}+\beta_{1} L N A T_{i t}+\beta_{2} I S N_{i t}+\beta_{3} D A C_{i t}+\beta_{4} I N T_{i t}+\beta_{5} I N V_{i t}+\varepsilon_{i t}
$$

em que: (i) ETR é a despesa com IRPJ e CSLL dividida pelo resultado antes dos impostos e participações multiplicado por 100; (ii) LNAT (tamanho) é o logaritmo natural (LN) do ativo total; (iii) ICA é a soma das contas de sinistros ocorridos, despesas com benefícios, custos de aquisição, outras receitas e despesas operacionais, resultado com resseguro, despesas administrativas e despesas com tributos dividida pela soma das contas de prêmios ganhos e receitas de contribuições, receita com emissão de apólices, receitas de contribuições e prêmios de VGBL, rendas com taxas de gestão e outras taxas, variação de outras provisões técnicas e resultado financeiro; (iv) IC é a soma das contas de sinistros ocorridos, despesas com benefícios, custos de aquisição, outras receitas e despesas operacionais, resultado com resseguro, despesas administrativas e despesas com tributos dividida pela soma das contas de prêmios ganhos e receitas de contribuições, receita com emissão de apólices, receitas de contribuições e prêmios de VGBL, rendas com taxas de gestão e outras taxas e variação de outras provisões técnicas; (v) ISN (sinistralidade) é a soma de sinistros ocorridos e despesas com benefícios dividida pela soma das contas de prêmios ganhos e receitas de contribuições, receita com emissão de apólices, receitas de contribuições e prêmios de VGBL, rendas com taxas de gestão e outras taxas e variação de outras provisões técnicas; (vi) DAC (custos diferidos) é o total dos custos de aquisição diferidos divididos pelo ativo total; (vii) INT (intangíveis) é o total dos ativos intangíveis dividido pelo ativo total, conforme Balanço Patrimonial (BP); e (viii) INV (participações societárias) é o total dos investimentos em participações societárias, incluindo eventuais reduções ao valor recuperável, dividido pelo ativo total, conforme BP.

A Tabela 2 apresenta o painel de variáveis usadas no estudo relacionando-as com as hipóteses enunciadas e os respectivos sinais esperados para os coeficientes estimados nos modelos utilizados.

Tabela 2 - Painel de Variáveis

\begin{tabular}{c|c|c|c}
\hline $\begin{array}{c}\text { Hipótese } \\
\text { Associada }\end{array}$ & Variável & Fórmula & $\begin{array}{c}\text { Sinal } \\
\text { esperado }\end{array}$ \\
\hline $\mathrm{H}_{1}$ & $\mathrm{ETR}_{\mathrm{it}}$ & (Desp. IR e CSLL / LAIR) X 100 & --- \\
\hline $\mathrm{H}_{2}$ & $\mathrm{LNAT}_{\mathrm{it}}$ & Logaritmo natural de ativo total & $(-)$ e sig. \\
\hline $\mathrm{H}_{3 \mathrm{a}}$ & $\mathrm{ICA}_{\mathrm{it}}$ & $\begin{array}{c}\sum(\mathrm{SO}, \mathrm{DB}, \mathrm{CA}, \mathrm{ORDO}, \mathrm{RR}, \mathrm{DA}, \mathrm{DT}) / \sum(\mathrm{PG}, \mathrm{REAP}, \\
\text { RCPVGBL, RTG, VOPT, RF) }\end{array}$ & $(-)$ e sig. \\
\hline $\mathrm{H}_{3 \mathrm{~b}}$ & $\mathrm{IC}_{\mathrm{it}}$ & $\begin{array}{c}\sum(\mathrm{SO}, \mathrm{DB}, \mathrm{CA}, \mathrm{ORDO}, \mathrm{RR}, \mathrm{DA}, \mathrm{DT}) / \sum(\mathrm{PG}, \mathrm{REAP}, \\
\text { RCPVGBL, RTG, VOPT })\end{array}$ & $(-)$ e sig. \\
\hline $\mathrm{H}_{3 \mathrm{c}}$ & $\mathrm{ISN}_{\mathrm{it}}$ & $\begin{array}{c}\sum(\mathrm{SO}, \mathrm{DB}) / \sum(\mathrm{PG}, \mathrm{REAP}, \mathrm{RCPVGBL}, \mathrm{RTG}, \mathrm{VOPT}, \mathrm{RF}) \\
(-) \text { e sig. }\end{array}$ \\
\hline $\mathrm{H}_{4}$ & $\mathrm{DAC}_{\mathrm{it}}$ & custos de aquisição diferidos / ativo total & $(+)$ e sig. \\
\hline $\mathrm{H}_{5}$ & $\mathrm{INT}_{\mathrm{it}}$ & ativos intangíveis / ativo total & $(-)$ e sig. \\
\hline $\mathrm{H}_{6}$ & $\mathrm{INV}_{\mathrm{it}}$ & $\begin{array}{c}\text { (investimentos em part. societárias (-) reduções ao valor } \\
\text { recuperável) / ativo total }\end{array}$ & $(-)$ e sig. \\
\hline
\end{tabular}

Fonte: Os autores, 2015.

Nota: $\mathrm{SO}=$ Sinistros Ocorridos; $\mathrm{DB}=$ Despesas com Benefícios; CA = Custos de Aquisição; ORDO = Outras Receitas e Despesas Operacionais; RR = Resultado com Resseguro ou Resultado com Retrocessão (resseguradores); DA $=$ Despesas Administrativas; DT $=$ Despesas com Tributos; PG $=$ Prêmios Ganhos e Receitas de Contribuições; REAP = Receita com Emissão de Apólices; RCPVGBL = Receita de Contribuições e Prêmios de VGBL; RTG = Rendas com Taxa de Gestão e Outras Taxas; VOPT = Variação de Outras Provisões Técnicas; e RF = Resultado Financeiro. 
Inicialmente, foram apuradas as estatísticas descritivas da variável ETR. Em seguida, fez-se teste de diferença de média para testar $\mathrm{H}_{1}$. Posteriormente, foi usada a análise de regressão linear múltipla em pooled para testar as hipóteses $\mathrm{H}_{2}$ a $\mathrm{H}_{6}$. Ademais, com o objetivo de testar a robustez dos resultados encontrados, uma nova variável independente foi utilizada, a LongETR, que acumula tanto os resultados antes dos tributos sobre o lucro quanto as despesas com tributos sobre o lucro de três exercícios, conforme Fórmula 4:

$$
\text { LongETR }=\frac{\mathrm{IR}_{\mathrm{i}, \mathrm{t}}+\mathrm{IR}_{\mathrm{i}, \mathrm{t}-1}+\mathrm{IR}_{\mathrm{i}, \mathrm{t}-2}+\mathrm{CSLL}_{\mathrm{it}}+\mathrm{CSLL}_{\mathrm{i}, \mathrm{t}-1}+\mathrm{CSLL}_{\mathrm{i}, \mathrm{t}-2}}{\mathrm{LAIR}_{\mathrm{i}, \mathrm{t}}+\mathrm{LAIR}_{\mathrm{i}, \mathrm{t}-1}+\mathrm{LAIR}_{\mathrm{i}, \mathrm{t}-2}} \times 100
$$

Trata-se de uma adaptação da variável Long-run cash ETR e Long Current ETR utilizada em estudos internacionais, conforme Hanlon e Heitzman (2010) e Lietz (2013). Espera-se que essa variável seja menos sensível à volatilidades de anos específicos, uma vez que se calcula uma alíquota efetiva acumulada de três exercícios. Além disso, evita-se que as relações encontradas sejam influenciadas apenas por accruals do ano mais recente. Notadamente, ao se utilizar uma variável com informações acumuladas de três períodos, perdem-se dois anos de observações, de modo que a LongETR foi calculada para os anos de 2010 a 2013 (HANLON; HEITZMAN, 2010).

Todas as análises foram realizadas com o apoio de ferramentas estatísticas informatizadas: o Statistical Package for the Social Sciences (SPSS), versão 20, para os testes de médias $\left(\mathrm{H}_{1}\right)$ e obtenção dos coeficientes padronizados dos regressores $\left(\mathrm{H}_{2}\right.$ a $\left.\mathrm{H}_{6}\right)$; e o programa Gretl, versão 1.9.15, na análise de regressão $\left(\mathrm{H}_{2}\right.$ a $\left.\mathrm{H}_{6}\right)$.

Finalmente, destacam-se algumas limitações metodológicas do estudo: os resultados reportados a seguir restringem-se à amostra trabalhada devido ao processo de amostragem adotado; os testes aplicados foram baseados em estudos anteriores, mas que não necessariamente se aplicam às especificidades do mercado analisado, para o qual não foram encontrados estudos anteriores sobre gerenciamento tributário; as subcontas usadas na composição dos indicadores usados podem ter sofrido alterações conceituais no período analisado.

\section{Análise dos Resultados}

As estatísticas descritivas da ETR em cada ano da amostra estão dispostas na Tabela 3. Em todos os períodos, as empresas que fazem parte da amostra apresentam uma ETR média inferior à alíquota nominal aproximada de $40 \%$.

Tabela 3 - Estatísticas descritivas, por exercício, da variável ETR para o período 2008-2013

\begin{tabular}{lrrrrrr}
\hline Medidas & \multicolumn{1}{r}{2008} & 2009 & 2010 & 2011 & 2012 & 2013 \\
\hline $\mathrm{N}$ & 81 & 91 & 102 & 96 & 93 & 80 \\
\hline Mín & 5,8126 & 5,9824 & 5,5754 & 6,0455 & 8,5647 & 11,7813 \\
\hline Máx & 56,038 & 51,9683 & 51,7739 & 47,2607 & 51,308 & 50,2649 \\
\hline Média & 31,04 & 30,443814 & 30,736934 & 31,340227 & 32,717661 & 33,825683 \\
\hline Desv. Pad. & 9,612568 & 10,659404 & 10,69199 & 9,697697 & 9,054776 & 7,728193 \\
\hline
\end{tabular}

Fonte: Os autores, 2015. 
Para confirmar a diferença das médias, foi inicialmente verificado que todas as subamostras anuais não passaram no teste de normalidade de Kolmogorov-Smirnov (K-S), para uma significância de $5 \%$, o que inviabiliza a realização de testes paramétricos. Diante disso, foi realizado o teste não paramétrico de Wilcoxon para amostras pareadas, comparando a alíquota média de cada ano à alíquota nominal aproximada de 40\% (Tabela 4). O teste de Wilcoxon é uma alternativa ao teste paramétrico $t$ de Student e pode ser usado quando a distribuição apresenta violação do pressuposto de normalidade (FÁVERO et al., 2009).

$\underline{\text { Tabela } 4 \text { - Resultados do teste de média para ETR }\left(\mathrm{H}_{1}\right)}$

\begin{tabular}{c|c|c|c}
\hline & & Teste K-S & Wilcoxon \\
\cline { 3 - 4 } Ano & Média & p-valor & p-valor \\
\hline 2008 & 31,04 & 0,024 & $<0,00001$ \\
\hline 2009 & 30,443814 & 0,001 & $<0,00001$ \\
\hline 2010 & 30,736934 & $<0,00001$ & $<0,00001$ \\
\hline 2011 & 31,340227 & 0 & $<0,00001$ \\
\hline 2012 & 32,717661 & 0,001 & $<0,00001$ \\
\hline 2013 & 33,825683 & 0,006 & $<0,00001$ \\
\hline
\end{tabular}

Fonte: Os autores, 2015.

Conforme o resultado apresentado na Tabela 4, todas as subamostras possuem uma alíquota média diferente e inferior à alíquota nominal, considerando-se a significância de 5\%, restando confirmada a hipótese $\mathrm{H}_{1}$. Ainda, há uma diferença de pouco mais de $3 \%$ entre a menor média $(30,44 \%$ em 2009) e a maior $(33,83 \%$ em 2013). O resultado do teste pode indicar a adoção de práticas de gerenciamento tributário das empresas de seguro pertencentes à amostra. Para saber se há diferença significativa entre as médias anuais foi realizado o teste não paramétrico de Kruskal-Wallis. O resultado revelou que não há diferença significativa entre as médias dos períodos $(\mathrm{p}$-valor $=0,166)$ o que parece indicar que não há efeito do ambiente econômico sobre a ETR.

Realizada esta análise preliminar, a Tabela 5 contém os resultados da regressão pooled de determinantes para ETR relativa aos dados pertencentes à amostra para o período de 2008 a 2013.

O modelo 1 é significante como um todo, pois apresenta $p$-valor $(\mathrm{F})<0,001$, sendo as variáveis independentes selecionadas capazes de explicar $17,77 \%\left(\mathrm{R}^{2}\right.$ ajustado) das variações da alíquota efetiva de tributos sobre o lucro.

Em relação aos possíveis determinantes selecionados, LNAT, proxy do tamanho, mostrou-se significativo ( $\mathrm{p}$-valor $<0,001$ ) e com sinal negativo, em linha com a hipótese $\mathrm{H}_{2}$, sugerindo que as grandes empresas conseguem reduzir os respectivos custos tributários. Esse resultado pode ser explicado pela capacidade diferenciada das maiores empresas de reduzir o custo com os tributos a partir da aplicação de planejamentos tributários em razão de deterem mais recursos.

Acerca do desempenho, o ICA revelou-se significativo ( $p$-valor $<0,001$ ) e com sinal negativo. Dessa forma, confirma-se $\mathrm{H}_{3 \mathrm{a}}$. $\mathrm{O}$ resultado vai ao encontro dos estudos de Gupta e Newberry (1997) e Richardson e Lanis (2007): empresas com melhores índices de desempenho apresentam uma alíquota efetiva maior. 
Gerenciamento Tributário: Evidências Empíricas no Mercado Segurador Brasileiro.

Tabela 5 - Resultados da regressão ETR $\left(\mathrm{H}_{2}\right.$ a $\left.\mathrm{H}_{6}\right)$

\begin{tabular}{|c|c|c|c|c|c|c|c|c|c|c|}
\hline \multirow[t]{2}{*}{ Variável } & \multirow[t]{2}{*}{ Sinal Esperado } & \multicolumn{3}{|c|}{$\begin{array}{c}\text { Modelo 1 } \\
(\text { proxy de desempenho = ICA })\end{array}$} & \multicolumn{3}{|c|}{$\begin{array}{c}\text { Modelo 2 } \\
\text { (proxy de desempenho = IC) } \\
\end{array}$} & \multicolumn{3}{|c|}{$\begin{array}{c}\text { Modelo 3 } \\
(\text { proxy de desempenho }=\text { ISN }) \\
\end{array}$} \\
\hline & & Coef. & Coef. Pad. & p-valor & Coef. & Coef. Pad. & p-valor & Coef. & Coef. Pad. & p-valor \\
\hline Const & & 50,088 & & $<0,001$ & 39,729 & & $<0,001$ & 41,796 & & $<0,001$ \\
\hline LNAT & $+/-$ & $-0,565$ & $-0,123$ & 0,003 & $-0,344$ & $-0,075$ & 0,070 & $-0,411$ & $-0,09$ & 0,030 \\
\hline ICA & - & $-7,819$ & $-0,170$ & $<0,001$ & NA & NA & NA & NA & NA & NA \\
\hline IC & - & NA & NA & NA & 0,002 & 0,005 & 0,907 & NA & NA & NA \\
\hline ISN & - & NA & NA & NA & NA & NA & NA & $-0,024$ & $-0,123$ & 0,002 \\
\hline DAC & + & 6,322 & 0,064 & 0,070 & 3,050 & 0,031 & 0,452 & 1,032 & 0,010 & 0,800 \\
\hline INT & - & $-57,057$ & $-0,151$ & 0,009 & $-64,260$ & $-0,170$ & $<0,001$ & $-62,645$ & $-0,165$ & $<0,001$ \\
\hline INV & - & $-40,035$ & $-0,307$ & $<0,001$ & $-41,001$ & $-0,314$ & $<0,001$ & $-39,617$ & $-0,304$ & $<0,001$ \\
\hline \multicolumn{2}{|l|}{$\mathrm{R}^{2}$} & \multicolumn{3}{|c|}{0,184} & \multicolumn{3}{|c|}{0,158} & \multicolumn{3}{|c|}{0,173} \\
\hline \multicolumn{2}{|l|}{$\mathrm{R}^{2}$ ajustado } & \multicolumn{3}{|c|}{0.177} & \multicolumn{3}{|c|}{0,151} & \multicolumn{3}{|c|}{0.165} \\
\hline \multicolumn{2}{|l|}{ P-valor (F) } & \multicolumn{3}{|c|}{$<0,001$} & \multicolumn{3}{|c|}{$<0,001$} & \multicolumn{3}{|c|}{$<0,001$} \\
\hline
\end{tabular}

Fonte: Os autores, 2015.

Nota: Pressupostos da análise de regressão: (a) premissa da normalidade violada, porém relaxada em virtude do tamanho da amostra contemplar 543 observações e em razão do teorema do limite central (BROOKS, 2002); (b) usou-se a correção de erros padrão robustos de White para a heterocedasticidade encontrada no modelo 1 (WOOLDRIDGE, 2006); (c) não houve violação quanto à homocedasticidade dos resíduos nos modelos 2 e 3 ; (d) não foi identificada multicolinearidade, pois todos os FIV (fatores de inflação de variância) ficaram próximos de 1; e (e) a autocorrelação serial não foi testada, pois os dados estão em pooled (FÁVERO et al., 2009).

Quanto ao mix de ativos, a variável relativa aos custos de aquisição diferidos (DAC) apresentou o sinal esperado, mas com significância estatística apenas a $10 \%$, sendo necessário avaliar os resultados dos modelos 2 e 3 para uma adequada avaliação de $\mathrm{H}_{4}$. Já as variáveis representativas dos ativos intangíveis (INT) e das participações societárias (INV) mostraramse significativas ( $\mathrm{p}$-valor $<0,001$ ) e com sinal negativo, conforme o esperado. Assim, confirmaram-se as hipóteses $\mathrm{H}_{5}$ e $\mathrm{H}_{6}$. Os coeficientes padronizados revelam que INV $(-0,307)$ seguido de ICA $(-0,170)$ são as variáveis que mais impactam a ETR.

Os modelos 2 e 3 estimam a ETR com as demais proxies relativas ao desempenho: IC e ISN. Procurou-se aprofundar as proxies em busca de especificidades do desempenho que expliquem as variações dos custos tributários, ou seja, verificar entre as medidas de performance qual delas corresponderia a um melhor determinante para a ETR e os possíveis motivos da relação encontrada.

Ainda de acordo com a Tabela 5, ambos os modelos são significativos como um todo, com p-valor $(\mathrm{F})<0,001$. Conforme $\mathrm{R}^{2}$ ajustado, as variáveis independentes selecionadas nos modelos 2 e 3 são capazes de explicar $15,1 \%$ e 16,5\%, respectivamente, das variações da ETR.

O desempenho avaliado por IC não resultou no sinal esperado e não apresentou significância $(p$-valor $=0,907)$. Já o ISN, além do sinal esperado, mostrou-se significativo ( $p$ valor $<0,001)$. Assim, tem-se a rejeição de $\mathrm{H}_{3 \mathrm{~b}}$ e a aceitação de $\mathrm{H}_{3 c}$.

Os resultados da estimação para as demais variáveis mostram que a proxy do ativo, LNAT tem relação inversa com a ETR, porém é significativa apenas a $10 \%(\mathrm{p}$-valor $=0,07)$ no modelo 2 , enquanto que no modelo 3 há significância a $5 \%(\mathrm{p}$-valor $=0,03)$, ratificando a aceitação de $\mathrm{H}_{2}$, ou seja, os resultados reforçam a hipótese de que as grandes empresas são mais eficientes na redução de seus custos tributários. A variável DAC apresentou o sinal esperado, mas não é significativa em ambos os modelos, o que, somado aos resultados do

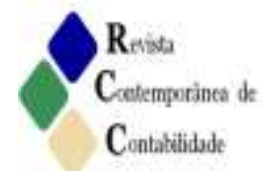


modelo 1 , faz com que seja rejeitada a $\mathrm{H}_{4}$. Por fim, as variáveis relativas aos intangíveis e participações societárias mostraram-se significativas em ambos os modelos ( $\mathrm{p}$-valor $<0,001)$ e com o sinal esperado. Esse resultado, também encontrado no modelo 1, aponta para a possibilidade de as empresas de seguro pertencentes à amostra se utilizarem dos benefícios fiscais de redução da carga tributária pela amortização de ágio reconhecido em processos de reorganização societária.

Nos modelos 2 e 3 houve alteração das variáveis que mais impactam a ETR, sendo a INV e a INT as que causam maior variação na ETR em ambos os modelos, conforme os coeficientes padronizados.

Considerando as hipóteses da pesquisa, confirmou-se a $\mathrm{H}_{2}$, conforme previsto: o tamanho das empresas do mercado segurador possui relação com a ETR e essa relação é inversa. Empresas de maior porte teriam uma alíquota efetiva menor, confirmando os achados de Cabello (2012), Gupta e Newberry (1997), Richardson e Lanis (2007) e Stickney e McGee (1982). Cabe apontar que o resultado vai de encontro à teoria do custo político explorada por Rego (2003). O resultado indica que as seguradoras de maior porte realizam escolhas que as conduzem a um menor custo com os tributos sobre o lucro.

Em relação aos indicadores de performance, razão da estimação pela técnica de regressão múltipla em três modelos, observou-se que o ICA é o que melhor explica a ETR. O ISN também demonstrou poder explicativo conforme resultado do modelo 3. Tais resultados indicam que um bom desempenho da empresa, avaliada tanto pelo ICA quanto pelo ISN, resulta em uma ETR maior em linha com os achados de Gupta e Newberry (1997) e Richardson e Lanis (2007). Quanto melhor a performance das empresas de seguro, medida pelo ICA ou pelo ISN, maior será a despesa tributária. Uma piora no desempenho - causada tanto pela redução de receitas quanto pelo aumento de despesas - reduz o lucro tributável. Entretanto, cabe destacar o papel das provisões técnicas na apuração do lucro fiscal. O resultado encontrado para os indicadores de performance reforça a possibilidade de as empresas de seguro gerenciarem a informação contábil de forma a reduzir, quando assim lhes convier, o custo com os tributos sobre o lucro, devido à dedutibilidade fiscal das provisões técnicas (RODRIGUES, 2008). Apenas o IC não se mostrou significativo, conforme os resultados do modelo 2. Assim, restam confirmadas $\mathrm{H}_{3 a}$ e $\mathrm{H}_{3 \mathrm{c}}$, para ICA e ISN.

A medida referente aos custos de aquisição diferidos não demonstrou poder explicativo sobre a ETR. Apesar de apresentar o sinal positivo esperado em todos os modelos, apenas no modelo 1 DAC demonstrou alguma significância e só a $10 \%$. Assim, $\mathrm{H}_{4}$ não pode ser confirmada. Em média, o maior ou menor diferimento dos custos associados à angariação dos negócios securitários parece não afetar a carga tributária das seguradoras da amostra.

As variáveis relacionadas com intangíveis e investimentos em participações societárias apresentaram significância em todos os modelos e relação inversa com a ETR, conforme

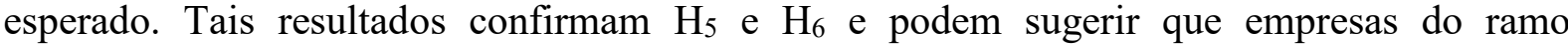
segurador realizam escolhas que impactam negativamente a ETR como o aproveitamento do custo do ágio em processos de reorganização societária, em linha com Cabello (2012) e Gomes (2012).

De forma a analisar a sensibilidade dos achados, a Tabela 6 apresenta os resultados de outros três modelos testados (modelos 4,5 e 6) com a LongETR como variável dependente. Cumpre registrar que a amostra contou, neste caso, com 299 observações, em razão de o cálculo da variável acumular dados de três anos, conforme a Fórmula 4 descrita na seção 3. 
Tabela 6 - Resultados da regressão LongETR $\left(\mathrm{H}_{2}\right.$ a $\left.\mathrm{H}_{6}\right)$ para os modelos 4 a 6

\begin{tabular}{|c|c|c|c|c|c|c|c|c|c|c|}
\hline \multirow[t]{2}{*}{ Variável } & \multirow[t]{2}{*}{ Sinal Esperado } & \multicolumn{3}{|c|}{$\begin{array}{c}\text { Modelo 4 } \\
\text { (proxy de desempenho = ICA }) \\
\end{array}$} & \multicolumn{3}{|c|}{$\begin{array}{c}\text { Modelo 5 } \\
(\text { proxy de desempenho = IC) } \\
\end{array}$} & \multicolumn{3}{|c|}{$\begin{array}{c}\text { Modelo 6 } \\
(\text { proxy de desempenho }=\text { ISN })\end{array}$} \\
\hline & & Coef. & Coef. Pad. & p-valor & Coef. & Coef. Pad. & p-valor & Coef. & Coef. Pad. & p-valor \\
\hline Const & & 58,6075 & & $<0,001$ & 47,463 & & $<0,001$ & 43,384 & & $<0,001$ \\
\hline LNAT & $+/-$ & $-0,8244$ & $-0,237$ & 0,0002 & $-0,571$ & $-0,164$ & 0,0026 & $-0,455$ & $-0,131$ & 0,0144 \\
\hline ICA & - & $-10,518$ & $-0,29$ & $<0,001$ & NA & NA & NA & NA & NA & NA \\
\hline $\mathrm{IC}$ & - & NA & NA & NA & $-2,049$ & $-0,157$ & 0,0026 & NA & NA & NA \\
\hline ISN & - & NA & NA & NA & NA & NA & NA & $-0,0135$ & $-0,102$ & 0,046 \\
\hline DAC & + & 4,121 & 0,059 & 0,207 & $-0,258$ & $-0,004$ & 0,9427 & $-1,051$ & $-0,015$ & 0,772 \\
\hline INT & - & $-50,745$ & $-0,157$ & $<0,001$ & $-63,008$ & $-0,194$ & 0,0003 & $-63,450$ & $-0,196$ & 0,0003 \\
\hline INV & - & $-49,707$ & $-0,346$ & $<0,001$ & $-50,725$ & $-0,353$ & $<0,001$ & $-50,185$ & $-0,349$ & $<0,001$ \\
\hline \multicolumn{2}{|c|}{$\overline{\mathrm{R}^{2}}$} & \multicolumn{3}{|c|}{0,31308} & \multicolumn{3}{|c|}{0,26698} & \multicolumn{3}{|c|}{0,25417} \\
\hline \multicolumn{2}{|c|}{$\mathrm{R}^{2}$ ajustado } & \multicolumn{3}{|c|}{0,30136} & \multicolumn{3}{|c|}{0,25447} & \multicolumn{3}{|c|}{0,24145} \\
\hline \multicolumn{2}{|l|}{ P-valor (F) } & \multicolumn{3}{|c|}{$<0,001$} & \multicolumn{3}{|c|}{$<0,001$} & \multicolumn{3}{|c|}{$<0,001$} \\
\hline
\end{tabular}

Fonte: Os autores, 2015.

Nota: Pressupostos da análise de regressão: (a) premissa da normalidade violada, porém relaxada em virtude do tamanho da amostra contemplar 299 observações e em razão do teorema do limite central (BROOKS, 2002); (b) usou-se a correção de erros padrão robustos de White para a heterocedasticidade encontrada no modelo 1 (WOOLDRIDGE, 2006); (c) não houve violação quanto à homocedasticidade dos resíduos nos modelos 5 e 6; (d) não foi identificada multicolinearidade, pois todos os FIV (fatores de inflação de variância) ficaram próximos de 1; e (e) a autocorrelação serial não foi testada, pois os dados estão em pooled (FÁVERO et al., 2009).

Os resultados encontrados a partir desses novos modelos mantêm os obtidos anteriormente, com exceção da variável IC, antes não significativa (modelo 2) e que passou a ser significativa no modelo 5. Essa alteração sugere que variações sazonais não pertinentes ao gerenciamento tributário podem ter alterado a relação entre o desempenho das firmas da amostra e a alíquota efetiva, de modo que a utilização de variável que considerou a média do período eliminou esse possível viés. De qualquer forma, o teste de robustez aplicado confirma as relações existentes entre o gerenciamento tributário e certas características das empresas do mercado de seguros pertencentes à amostra: (a) empresas de maior porte conseguem ter um menor custo com os tributos sobre o lucro; (b) seguradoras com melhores índices de performance tendem a ter maior custo com os tributos, podendo se utilizar da discricionariedade na contabilização de despesas com provisões de sinistros para reduzir esse custo; e (c) há uma relação inversa entre o custo com os tributos e as contas de intangíveis e de investimentos em participações societárias, o que pode indicar o aproveitamento da amortização de ágio decorrente de reorganizações societárias.

\section{Conclusões}

Este estudo procurou evidências empíricas da prática de gerenciamento tributário em empresas do mercado segurador, diferenciando-se, portanto, das pesquisas anteriores quanto à população. Vale ressaltar que a citada prática visa reduzir a carga fiscal a que estão submetidas as pessoas jurídicas pela adoção de determinadas escolhas contábeis e que a alíquota nominal do setor estudado é maior do que a dos demais.

A alíquota efetiva dos tributos sobre o lucro (ETR) média encontrada para os períodos

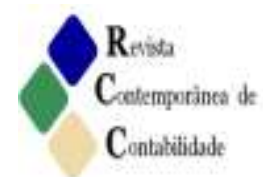


analisados é inferior à alíquota nominal estimada de IRPJ e CSLL para o setor (40\%). Em cada ano da amostra, a ETR é aproximadamente $9 \%$ inferior à alíquota nominal. O teste estatístico não paramétrico realizado confirmou $\mathrm{H}_{1}$; a ETR média de cada um dos anos analisados é reduzida. Isso mostra indícios de que as sociedades seguradoras, entidades abertas de previdência complementar e resseguradores locais podem estar se utilizando de práticas de gerenciamento tributário.

Além da detecção de indícios de gerenciamento, buscou-se identificar características das empresas do mercado segurador que pudessem influenciar a variação da ETR. A partir de modelos aplicados em estudos anteriores sobre gerenciamento tributário em outros mercados, foi utilizada a técnica de regressão linear múltipla de forma a verificar se o tamanho, desempenho, diferimento de custos de aquisição, intangíveis e investimentos em participações societárias podem explicar a ETR.

Foi identificado que as maiores empresas do mercado segurador apresentam menores taxas efetivas, confirmando $\mathrm{H}_{2}$. Isso vai ao encontro dos achados de Cabello (2012), Gupta e Newberry (1997), Richardson e Lanis (2007) e Stickney e McGee (1982) e pode estar associado à maior capacidade das grandes empresas de influenciar politicamente o processo tributário, desenvolver a expertise em planejamento e organizar suas atividades numa forma ótima de economia de impostos. Assim, não se encontraram evidências da hipótese dos custos políticos detectada por Rego (2003).

Ademais, o desempenho operacional favorável das empresas do mercado segurador implica maiores taxas efetivas, resultado que se coaduna com os resultados de Gupta e Newberry (1997) e Richardson e Lanis (2007) e contraria os achados de Mills, Newberry e Trautman (2002) e Rego (2003). O índice combinado ampliado (ICA) e o índice de sinistralidade (ISN) apresentaram forte significância e sinal negativo, indicando que empresas com melhores desempenhos tendem a apresentar maiores custos tributários, enquanto que aquelas com piores desempenhos tendem a gerenciar os tributos sobre o lucro, reduzindo-os.

Portanto, resta confirmada a $\mathrm{H}_{2}$, ainda que isso só ocorra quando considerado o resultado financeiro no indicador de desempenho (ICA) ou o índice de sinistralidade (ISN). O índice combinado (IC), que avalia a performance da operação de seguro desconsiderando o resultado financeiro, não se mostrou significativo inicialmente. Considerando o ambiente brasileiro com taxas de juros elevadas, que podem propiciar elevados ganhos, o resultado encontrado demonstra que a melhoria operacional das companhias estudadas, quando considerado o resultado financeiro, gera maiores resultados globais e, por conseguinte, maiores custos tributários.

Se considerado o desempenho sem o resultado financeiro (IC), a melhoria da operação não gera impacto significativo na ETR, induzindo ao raciocínio de que o IC é calculado, em sua maior parte, a partir de receitas tributáveis e despesas dedutíveis, os quais não influenciam a alíquota efetiva de tributos sobre o lucro.

A sinistralidade (ISN) também se mostrou significativa e negativamente relacionada com a ETR, possivelmente devido ao uso dos erros de estimação das provisões de sinistros para redução de tributos, conforme achados de Beaver, McNichols e Nelson (2003), Gaver e Paterson (1999), Grace (1990), Nelson (2000) e Rodrigues (2008). Isso se torna possível devido ao alto grau de discricionariedade inerente à mensuração inicial e subsequente das provisões de sinistros, conforme menciona Grace e Leverty (2012).

O teste de sensibilidade com uma ETR de longo prazo confirmou que as seguradoras com melhor performance, mesmo sem considerar os resultados financeiros, apresentam 
maiores custos com tributos, conforme previsto. Com a diluição dos efeitos dos accruals no custo dos tributos, o índice combinado (IC) passou a ser significativo.

$\mathrm{O}$ custo de aquisição diferido não se mostrou significativo, não sendo possível confirmar a $\mathrm{H}_{4}$, contrariando os achados de Gupta e Newberry (1997), Richardson e Lanis (2007) e Stickney e McGee (1982). Procurou-se neste trabalho fazer uma aproximação com estudos anteriores que apontaram a relação entre ETR e estoques. Entretanto, a variável DAC só apresentou uma baixa significância em um dos três modelos usados neste trabalho.

Por fim, o intangível (INT) mostrou-se significativo e com sinal negativo, assim como a variável relativa às participações societárias (INV), confirmando $\mathrm{H}_{5}$ e $\mathrm{H}_{6}$. Isso sugere que as seguradoras, as entidades de previdência e os resseguradores locais podem estar se utilizando de práticas de gerenciamento tributário decorrentes de reorganizações societárias com utilização de reduções nos tributos motivadas por ágio. Esses resultados estão alinhados aos de Cabello (2012) e Gomes (2012).

Apesar das limitações descritas na metodologia, avaliar a realização dessas práticas contribui para o aumento do conhecimento sobre o fenômeno do gerenciamento tributário, para a avaliação dos participantes do mercado acerca dos custos de transação decorrentes das escolhas e para o incremento e o aprimoramento das técnicas de regulação e controle usados pelo agente regulador do mercado e pelas autoridades tributárias.

Trabalhos futuros podem (i) estudar o gerenciamento tributário no mercado segurador por meio de outras variáveis capazes de capturar o fenômeno, como a CashETR, a BTD ou a CurrentETR, capturando-as a partir das demonstrações contábeis publicadas; (ii) relacionar características de governança corporativa ao gerenciamento tributário; (iii) aprofundar o entendimento de quais fatos contábeis relacionados ao intangível, aos investimentos e ao resultado financeiro impactam a ETR das companhias do mercado segurador brasileiro; e (iv) utilizar o período pré-convergência deste mercado.

\section{Referências}

BEAVER, W. H.; MCNICHOLS, M. F.; NELSON, K. K. Management of the loss reserve accrual and the distribution of earnings in the property-casualty insurance industry. Journal of Accounting and Economics, Amsterdam, v. 35, n. 3, p. 347-376, Aug. 2003.

BRASIL. Decreto n. 3000, de 26 de março de 1999. Regulamenta a tributação, físcalização, arrecadação e administração do Imposto sobre a Renda e proventos de qualquer natureza. Diário Oficial [da] República Federativa do Brasil, Brasília, DF, 29 mar. 1999. Disponível em: <https://www.planalto.gov.br/ccivil_03/decreto/D3000.htm>. Acesso em: 6 dez. 2014.

Decreto-Lei n. 73, de 21 de novembro de 1966. Dispõe sobre o Sistema Nacional de Seguros Privados, regula as operações de seguros e resseguros e dá outras providências. Diário Oficial [da] República Federativa do Brasil, Brasília, DF, 22 nov. 1966. Disponível em: <http://www.planalto.gov.br/ccivil_03/Decreto-Lei/del0073compilado.htm>. Acesso em: 6 dez. 2014.

Lei n. 7.689, de 15 de dezembro de 1988. Institui contribuição social sobre o lucro

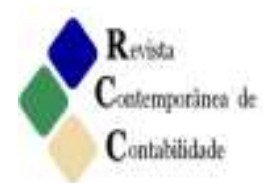


das pessoas jurídicas e dá outras providências. Diário Oficial [da] República Federativa do Brasil, Brasília, DF, 16 dez. 1988. Disponível em: $<$ http://www.planalto.gov.br/ccivil_03/_ato2007-2010/2008/lei/111727.htm>. Acesso em: 3 dez. 2014.

Lei n. 9.532, de 10 de dezembro de 1997. Altera a legislação tributária federal e dá outras providências. Diário Oficial [da] República Federativa do Brasil, Brasília, DF, 11 dez. 1997. Disponível em: <http://www.planalto.gov.br/ccivil_03/leis/L9532.htm>. Acesso em: 6 dez. 2014.

Lei n. 13.169, de 6 de outubro de 2015. Altera a Lei $\mathrm{n}^{0}$ 7.689, de 15 de dezembro de 1988, para elevar a alíquota da Contribuição Social sobre o Lucro Líquido - CSLL em relação às pessoas jurídicas de seguros privados e de capitalização e às referidas nos incisos I a VII, IX e X do $\S 1^{\circ}$ do art. $1^{\circ}$ da Lei Complementar $n^{\circ} 105$, de 10 de janeiro de 2001 e dá outras providências. Diário Oficial [da] República Federativa do Brasil, Brasília, DF, 7 de outubro de 2015. Disponível em: <http://www.planalto.gov.br/ccivil_03/_Ato20152018/2015/Lei/L13169.htm>. Acesso em: 3 nov. 2015.

. Superintendência de Seguros Privados. Fiscalização à distância. Rio de Janeiro, 2015. 14 p. Disponível em: <http://www.susep.gov.br/setoressusep/cgsoa/Fiscalizacao\%20a\%20Distancia\%202015.pdf/view>. Acesso em: 2 mar. 2015.

BROOKS, C. Introductory econometrics for finance. Cambridge: Cambridge University Press, 2002.

CABELLO, O. G. Análise dos efeitos das práticas de tributação do lucro na Effective Tax Rate (ETR) das companhias abertas brasileiras: uma abordagem da teoria das escolhas contábeis. 2012. 144 f. Tese (Doutorado em Controladoria e Contabilidade: Contabilidade) Programa de Pós-Graduação em Ciências Contábeis, Departamento de Contabilidade e Atuária, Faculdade de Economia, Administração e Contabilidade da Universidade de São Paulo, São Paulo, 2012.

CHEN, S.; CHEN, X.; CHENG, Q.; SHEVLIN, T. Are family firms more aggressive than non-family firms? Journal of Financial Economics, Lausanne, v. 95. n. 1, p 41-61, Jan. 2010 .

CONTADOR, C. Economia do seguro: fundamentos e aplicações. São Paulo: Atlas, 2007.

DESAI, M. A.; DHARMAPALA, D. Earnings management, corporate tax shelters, and booktax alignment. National Tax Journal, Columbus, v. 62, n. 1, p. 169-186, Mar. 2009.

FÁVERO, L. P.; BELFIORE, P.; SILVA, F. L.; CHAN, B. L. Análise de dados: Modelagem Multivariada para Tomada de Decisões. Rio de Janeiro: Elsevier, 2009.

FIELDS, T. D.; LYS, T.Z.; VINCENT, L. Empirical research on accounting choice. Journal of Accounting and Economics, Amsterdam, v. 31, n. 1, p. 255-307, Sept. 2001. 
GAVER, J. J.; PATERSON, J. S. Managing insurance company financial statements to meet regulatory and tax reporting goals. Contemporary Accounting Research, Toronto, v. 16, n. 2, p. 207-241, Summer 1999.

Do insurers manipulate loss reserves to mask solvency problems? Journal of Accounting and Economics, Amsterdam, v. 37, p. 393-416, Sept. 2004.

GOMES, A. P. M. A influência das características da governança corporativa na gestão tributária das empresas brasileiras. 2012. 147 p. Dissertação (Mestrado em Ciências Contábeis) - Programa de Pós-Graduação em Ciências Contábeis, Faculdade de Ciências Econômicas, Universidade Federal de Minas Gerais, Minas Gerais, 2012.

GRACE, E. V. Property-liability insurer reserve errors: a theoretical and empirical analysis. The Journal of Risk and Insurance, Orlando, v. 57, n. 1, p. 28-46, Mar. 1990.

GRACE, M. F.; LEVERTY, J. T. Property-liability insurer reserve error: motive, manipulation, or mistake. The Journal of Risk and Insurance, Orlando, v. 79, n. 2, p. 351380, June 2012.

GRAHAM, J. R.; RAEDY, J. S.; SHACKELFORD, D. A. Research in accounting for income taxes. Journal of Accounting and Economics, Amsterdam, v. 53, n. 1-2, p. 412-434, Feb.Apr. 2012.

GUPTA, S.; NEWBERRY, K. Determinants of the variability in corporate effective tax rates: Evidence from longitudinal data. Journal of Accounting and Public Policy, Maryland, v. 16, n. 1, p. 1-34, Spring 1997.

HANLON, M.; HEITZMAN, S. A Review of tax research. Journal of Accounting and Economics, Amsterdam, v. 50, n. 2-3, p. 127-178, Dec. 2010.

LIETZ, G. Tax avoidance vs. Tax aggressiveness: A unifying conceptual framework. Working Paper, University of Münster, 2013. Disponível em: $<$ http://ssrn.com.abstract=2363828>. Acesso em: 3 nov. 2015.

MAYDEW, E. L. Empirical tax research in accounting: A discussion. Journal of Accounting Research, Chicago, v. 31, n. 1-3, p. 389-403, Sept. 2001.

MAYERS, D.; SMITH JR., C. W. Contractual provisions, organizational structure, and conflict control in insurance markets. The Journal of Business, Chicago, v. 54, n. 3, p. 407434, July 1981.

MELO, E. F. L.; NEVES, C. R. Avaliação de ativos e obrigações de seguradoras para fins de solvência. In: - Solvência no mercado de seguros e previdência: coletânea de estudos. Rio de Janeiro: Escola Nacional de Seguros - Funenseg, 2012. cap. 1.

MILLS, L.; NEWBERRY, K; TRAUTMAN, W. B. Trends in book-tax income and balance sheet differences. Tax Notes, Falls Church, v. 96, n. 8, p. 491-521, Aug. 2002. 
NELSON, K. K. Rate regulation, competition, and loss reserve discounting by propertycasualty insurers. The Accounting Review, Sarasota, v. 75, n. 1, p. 115-138, Jan. 2000.

PETRONI, K. Optimistic reporting in the property-casualty insurance industry. Journal of Accounting and Economics, Amsterdam, v. 15, p. 485-508, Dec. 1992.

PROVIDENTE, V. M. A estrutura de propriedade e o conselho de administração como mitigadores dos custos de agência: uma análise empírica do mercado segurador brasileiro. 2015. 114 f. Dissertação (Mestrado Profissional em Economia) - Faculdade de Economia e Finanças, Instituto Brasileiro de Mercado de Capitais, Rio de Janeiro, 2015.

REGO, S. O. Tax-avoidance activities of U.S. multinational corporations. Contemporary Accounting Research, Toronto, v. 20, n. 4, p. 805-833, Winter 2003.

RICHARDSON, G.; LANIS, R. Determinants of the variability in corporate effective tax rates and tax reform: evidence from Australia. Journal of Accounting and Public Policy, Maryland, v. 26, n. 6, p. 689-704, Nov.-Dec. 2007.

RODRIGUES, A. Gerenciamento da informação contábil e regulação: evidências no mercado brasileiro de seguros. 2008. 150 f. Tese (Doutorado em Controladoria e Contabilidade) - Programa de Pós-Graduação em Ciências Contábeis, Departamento de Contabilidade e Atuária, Faculdade de Economia, Administração e Contabilidade da Universidade de São Paulo, São Paulo, 2008.

SHACKELFORD, D. A.; SHEVLIN, T. J. Empirical tax research in accounting. Journal of Accounting and Economics, Amsterdam, v. 31, n. 1-3, p. 321-387, Sept. 2001.

SILVA, A. Contabilidade e análise econômico-financeira de seguradoras. São Paulo: Atlas, 1999.

SILVA, A. C. R. Metodologia da pesquisa aplicada à contabilidade: orientações de estudos, projetos, artigos, relatórios, monografias, dissertações, teses. 3. ed. São Paulo: Atlas, 2010.

SHOLES, M.; WOLFSON, M. The effects of changes in tax laws on corporate reorganization activit. Journal of Business, 63, p. S141-S164, 1990.

STICKNEY, C. P.; MCGEE, V. E. Effective corporate tax rates the effect of size, capital intensity, leverage, and other factors. Journal of Accounting and Public Policy, Maryland, v. 1, n. 2, p. 125-152, Winter 1982.

TANG, T. Y. H. Book-tax differences, a proxy for earnings management and tax management-empirical: evidence from China. $S S R N$, The International Journal of Accounting, Jan. 2005. Disponível em: $<$ http://ssrn.com/abstract=872389>. Acesso em: 30 July 2014.

WOOLDRIDGE, J. M. Introdução à econometria: uma abordagem moderna. São Paulo: 
Pioneira Thomson Learning, 2006.

ZANCHET, A.; MARQUES, C.; MARTINS, G. Epistemologia das abordagens metodológicas na pesquisa contábil: do normativismo ao positivismo. In: XXXV ENCONTRO DA ENANPAD. Rio de Janeiro. Anais... Rio de Janeiro, 2011. 